\title{
SPATIOTEMPORAL VISIBILITY CHARACTERISTICS IMPACTED BY FOREST AND LAND FIRE OVER AIRPORTS IN SUMATERA AND BORNEO ISLAND, INDONESIA
}

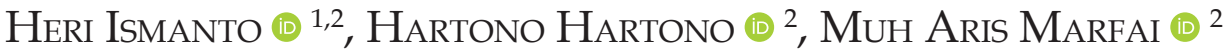 \\ ${ }^{1}$ Meteorology, Climatology, and Geophysical Agency, Jakarta, Indonesia \\ ${ }^{2}$ Faculty of Geography, Universitas Gadjah Mada, Yogyakarta, Indonesia
}

Manuscript received: March 8, 2018

Revised version: July 7, 2019

\begin{abstract}
Ismanto H., Hartono H., Marfai M.A., 2019. Spatiotemporal visibility characteristics impacted by forest and land fire over airports in Sumatera and Borneo Island, Indonesia. Quaestiones Geographicae 38(3), Bogucki Wydawnictwo Naukowe, Poznań, pp. 5-16. 5 figs, 3 tables.

ABSTRACT: Smoke can reduce the airport's visibility and is related to the aviation safety and efficiency. Low visibility has potential safety hazard, such GA-152 crashed in 1997, and thus there is a need to find out the visibility characteristics in airports over Sumatra and Borneo Island caused by 2015 forest fire. This research aims to analyse the spatiotemporal visibility characteristics over airports in Sumatera and Borneo Island using flight rule visibility below minima criteria and hazard probability. The analysis of smoke was characterized using visibility severity index (VSI) that is a function of visibility severity class and its probability level. Spatiotemporal analysis of severity index combined with hotspot and wind numerical weather model indicates that the worst impact visibility occurred in September and October 2015. The lowest visibility was occured over night until afternoon time period. The spread of VSI impact has a tendency to northward and northwestward. The very high VSI levels occurred at airports such: WIJJ (Jambi), WIBB (Pekanbaru), WAGG (Palangkaraya) which were impacted up to $70 \%$ of flight operations time with IFR visibility below minima; while the WIOS (Susilo-Sintang), which operates only on VFR, experienced about 92\% of VFR visibility below minima at smoke climax period.
\end{abstract}

KEY WORDS: smoke, weather minima, visibility severity index, airport, Sumatra, Borneo

Corresponding author: Muh Aris Marfai, arismarfai@ugm.ac.id

\section{Introduction}

Atmospheric visibility, human health, and climate radiative forcing was adversely affected by smoke produced from large biomass burning (Saide et al. 2015, Aiken 2004). Indonesian Smoke 2015 event was the worst's that it's been for the last 20 years (McKirdy 2015). At least 500 Garuda Indonesia Airline and 250 Citilink flights had to be cancelled throughout September 2015, due to smoke currently affecting several areas such
Jambi, Palangkaraya (Central Borneo), Pontianak (West Borneo) and Riau (Gunawan 2015). Bad weather, including low visibility, is the major factor in aircraft accidents (Jenamani, Kumar 2013). Hazard occurrence had a potential loss, herewith research is needed to support the alleviation measures that impact and affect human life (Afrianto et al. 2015).

Hazard characterization and maps plays a fundamental role in the risk assessment process and hazard management policies. Various 
studies have been conduct in such research: the landslide hazard analysis that very important in land planning, design and dimensioning of mitigating structure (Lari et al. 2014). The use of relatife frequencies of rockfall runout assesment, to establish hazard and risk maps at regional scale (Michoud et al. 2012). The cumulative impact of the various influencing parameters that exacerbates the seismic hazard risk of the valley to future earthquake events (Rashid et al. 2018).

Smoke is caused by suspended solid particles formed by the combustion of object. It can also directly influence horizontal visibility and creates obscured vision (CWB, n.d.). Meanwhile, the World Meteorological Organization (1992) in Heil and Goldammer (2001) define haze as a suspension of extremely small, dry particles in the atmosphere and hence does not specify a specific source. Smoke has a close relationship with aviation safety. Garuda Indonesia flight number GA 152 accident, all 234 passengers had been dead, at Medan September 26, 1997, happened in a smoky environment (Aiken 2004). Hazard weather related is one of the main causes of air accidents, excluding human errors, mechanical failures, sabotages and military operations (Janic 2000).

The impact level of the hazard on flight operation depends on the type of flight rules. Visual flight rule (VFR) require pilots to monitor weather conditions (including visibility) by vision. The best strategy for a potentially vulnerable pilot when facing a visibility weather minima situation according to flight rules is to avoid the landing (Herzegh et al. 2015). If the airport, plane, and pilot have the capacity to fly with instruments (Instrument Flight Rule/IFR), the visual limitations of the eye can be replaced by consideration of instrument information. Flying with instrument rules has less vulnerability than visual (VFR) when entering the airport with low visibility (Jenamani, Kumar 2013).

Traditionally the focus of research on aviation safety has been on analyzing accidents, investigating their causes and recomending corrective action. More recently, in addition to this reactive approach to improving aviation safety, increased emphasis has been placed on taking a proactive approach. This approach involves identifying emerging risk factors, characterizing these risk, and making recomendations with regrad to necessary improvement and what factors contributed to the accident (ICAO 2013, Oster et al. 2013). Hazard is one of the factor related to the aviation safety. In frame of proactive approach, identifying and characterizing of adverse weather (smoke visibility hazard) is one of the effort to conduct the reducing risk of the aviation. There is a need to analyse the visibility characteristics over airports in Sumatera and Borneo Island due to smoke effect caused by 2015 forest and land fire. It is useful for evaluation and taking preventive action to reduce the smoke impact on aviation safety.

The research aims to analyse the spatiotemporal impact of forest and land fire to visibility over airports in the research area. By using take-off and landing data weather observation (METAR), hotspot, and wind from numerical weather model, the research is conduct to explore monthly, daily and severity characteristic of visibility caused by smoke. This study is different from previous research because using ground actual visibility observation over airport other than remote sensing/modelling data (Xian et al. 2013, Ismanto et al. 2018) and analysing it using probability and severity analysis related to flight operation and aviation safety (Balarabe et al. 2015, Wang, Field 2004).

\section{Materials and Methods}

The study area consists of the airports in Sumatra and Kalimantan Island of Indonesia which are located $6.8^{\circ} \mathrm{S}$ to $6.8^{\circ} \mathrm{N}$ and $95^{\circ} \mathrm{E}$ to $120^{\circ} \mathrm{E}$. The object point of the study was 47 airports that carried out actual weather observations (METAR) for aviation safety (Fig. 1). The research time period started from July $1^{\text {st }}, 2015$ at 00:00 UTC (07:00 WIB/local time) to 31 December 2015 at 23:59 UTC (06:59 WIB/local time). Smoke was directly reported in the METAR by weather observer, is referred to as FU (fume, France) followed by the visibility condition. The weather phenomena only limited to smoke, excluding haze phenomena. METAR is useful for flight crew prior to dispatch, enroute and adequate planning of the approach and landing. Actual weather and prevailing visibility (the greatest visibility value which is reached at least within half the horizon circle or within half of the aerodrome surface (ICAO 2011)) data has been used to be temporally and spatially analysed at each airport. 
The aerodrome weather observation data (METAR) varies on each airport, data availability follows the Asia Pacific regional navigation agreement. Four-digit ICAO Airport code information was downloaded from their webpage. Data density includes 30 minutes, hour or 3 hours (because of data communication problem). It is operating time distance of 6 hours, 12 hours and 24 hours. The total number of METAR observations each airport is the summation of total number of METAR observations used in this study. It used to calculate the frequentist probability of smoke occurrences.

The hotspot data was used to determine the sources of fire, which taken from the National Aeronautics and Space (LAPAN Indonesia) TERRA and AQUA satellites analysis. This daily temporal data contained the location of hotspot data (latitude and longitude) and a degree of confidence, only hotspot with the degree of confidence greater than $50 \%$, middle confidence level hotspot (Hantson et. al. 2013), would be analysed.

Smoke from forest and land fire was strongly influenced by climate factors (including wind direction and speed) (Widodo et al. 2017). Wind from European Center for Medium-Range Weather Forecasts (ECMWF 2018) numerical weather model data, ERA5 Reanalysis, provides gridding climatological data. The average monthly winds level 925 mbar ( $\pm 762 \mathrm{~m}$ ) data was used to analyse the propagation of smoke impact (Heil et al. 2006). This $0.5 \times 0.5$-degree data was downloaded from ECMWF (2018).

The research method used temporal and spatial categorical analysis of visibility severity index (VSI). First, the categories used were based on the visibility weather minima in rules of flight operations (Table 1). Second, the probability of each category, to be analysed in the monthly period, is

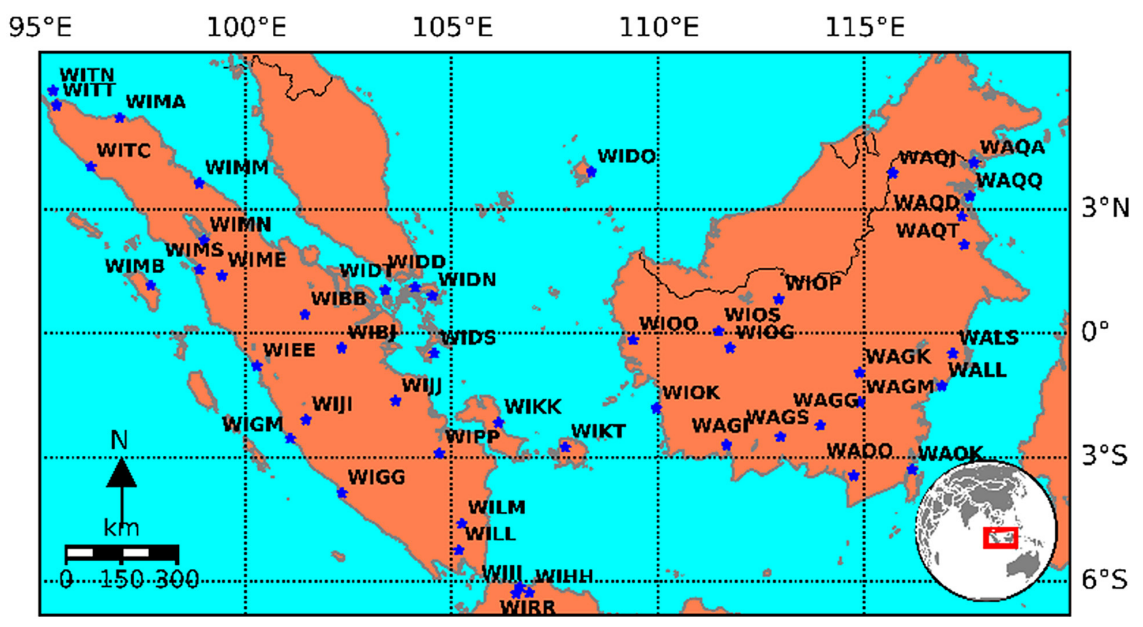

Fig. 1. Research Area and Airports location.

Table 1. Visibility below minima criteria for VFR and IFR (Glahn et al. 2015., Rudack, Ghirardelli 2010, FAA 2009, DGCA 2015).

\begin{tabular}{|c|c|c|c|}
\hline Class & Flight Rule & Minimum Visibility Condition & Scale \\
\hline H1 & VFR (Visual Flight Rule) & More than $4.8 \mathrm{~km}(>3 \mathrm{SM})$ & 1 \\
\hline H2 & SVFR (Special Visual Flight Rule) & $3.2-4.8 \mathrm{~km}(2-3 \mathrm{SM})$ & 2 \\
\hline H3 & IFR (Instrument Flight Rule I) & $1.6-3.2 \mathrm{~km}(1-2 \mathrm{SM})$ & 3 \\
\hline H4 & LIFR (instrument Flight Rule II) & Less than $1600 \mathrm{~m}(<1 \mathrm{SM})$ & 4 \\
\hline
\end{tabular}

Table 2. Probability of occurrence (State-Argentina 2016).

\begin{tabular}{|l|l|c|}
\hline \multicolumn{1}{|c|}{ Probability } & \multicolumn{1}{c|}{ Explanation } & Prob (Scale) \\
\hline Frequent & occurred frequently, probability more than 0.7 & 5 \\
\hline Occasional & occurred infrequently, probability is $0.5 \mathrm{~s} / \mathrm{d} 0.7$ & 4 \\
\hline Remote & occurred rarely), probability is $0.1 \mathrm{~s} / \mathrm{d} 0.5$ & 3 \\
\hline Improbable & not known to have occurred, probability $0.01 \mathrm{~s} / \mathrm{d} 0.1$ & 1 \\
\hline Extremely improbable & Impossible to occur, probability less than 0.01 & 1 \\
\hline
\end{tabular}


provided according to Table 2 . Visibility severity index was counted based on these two parameters, as shown in below equation. Probability was calculated based on the occurance of class-flight rule devided by total number of METAR observations in a month. Each class-flight rule have their own probability in each month. Calculation of VSI is illustrate the total hazard (visibility classes of flight rule) with their probability of occurences.

Probability theory is the body of knowledge that enables us to reason formally about uncertain events. The populist view of probability is the so-called frequentist approach whereby the probability $\mathrm{P}$ of an uncertain event $\mathrm{A}$, written $\mathrm{P}(\mathrm{A})$, is defined by the frequency of that event based on past observations/experience (Baccini, 2001). For example in this paper, occurrence frequency of smoke happen in airport $\mathrm{X}$ is $70.9 \%$ at the certain month; suppose then that we are interested in the event A: 'a randomly selected at certain time of that month on airport $X$, smoke is been occured'. According to the frequentist approach $\mathrm{P}(\mathrm{A})=0.709$. The calculation of the impact of visibility on airports was calculated based on the accumulated probability $(\mathrm{P}(\mathrm{h} 1), \mathrm{P}(\mathrm{h} 2)$, $\mathrm{P}(\mathrm{h} 3), \mathrm{P}(\mathrm{h} 4)$ ) of each categorical visibility class. Calculated based on the equation:

$$
\begin{gathered}
V S I=(H 1 \times P(h 1))+(H 2 \times P(h 2))+(H 3 \times P(h 3))+ \\
+(H 4 \times P(h 4)) .
\end{gathered}
$$

VSI (Visibility Severity Index): The accumulated value of the Visibility class multiplied by the probability of events in a such period; H1, H2, H3 and H4: are hazard class based on flight rule criteria, for example: class H1 (hazard class that visibility range more than 4800 meters or 3 $\mathrm{SM})$ gifted " 1 " as index scale because this class is lest impact on flight operation, except for VFR. The hazard index is raising related to the raising of flight operation hazard class impact (Table 1) $\mathrm{P}(\mathrm{h} 1)$ : frequentist probability of $\mathrm{H} 1$ class. For example: visibility class $\mathrm{H} 1$ occur 60 times at observation time at certain month, the total observation time in a month are 270 . Frequentist probability ( $\mathrm{P}(\mathrm{h} 1)$ ) is 60/270 (approximately 0.23). It means that hazard class $\mathrm{H} 1$ is rarely occurred and then to be indexed as 3 (Table 2). VSI calculation is based on all hazard visibility classes accumulation (visibility minimum criteria and frequentist probability of each class).

\section{Results and discussion}

\section{Monthly Characteristics of Smoke Hazards at Mid-End 2015}

Figure 2 showed the monthly variation of visibility over airports in the study area. The vertical axis on the left presents the airports that

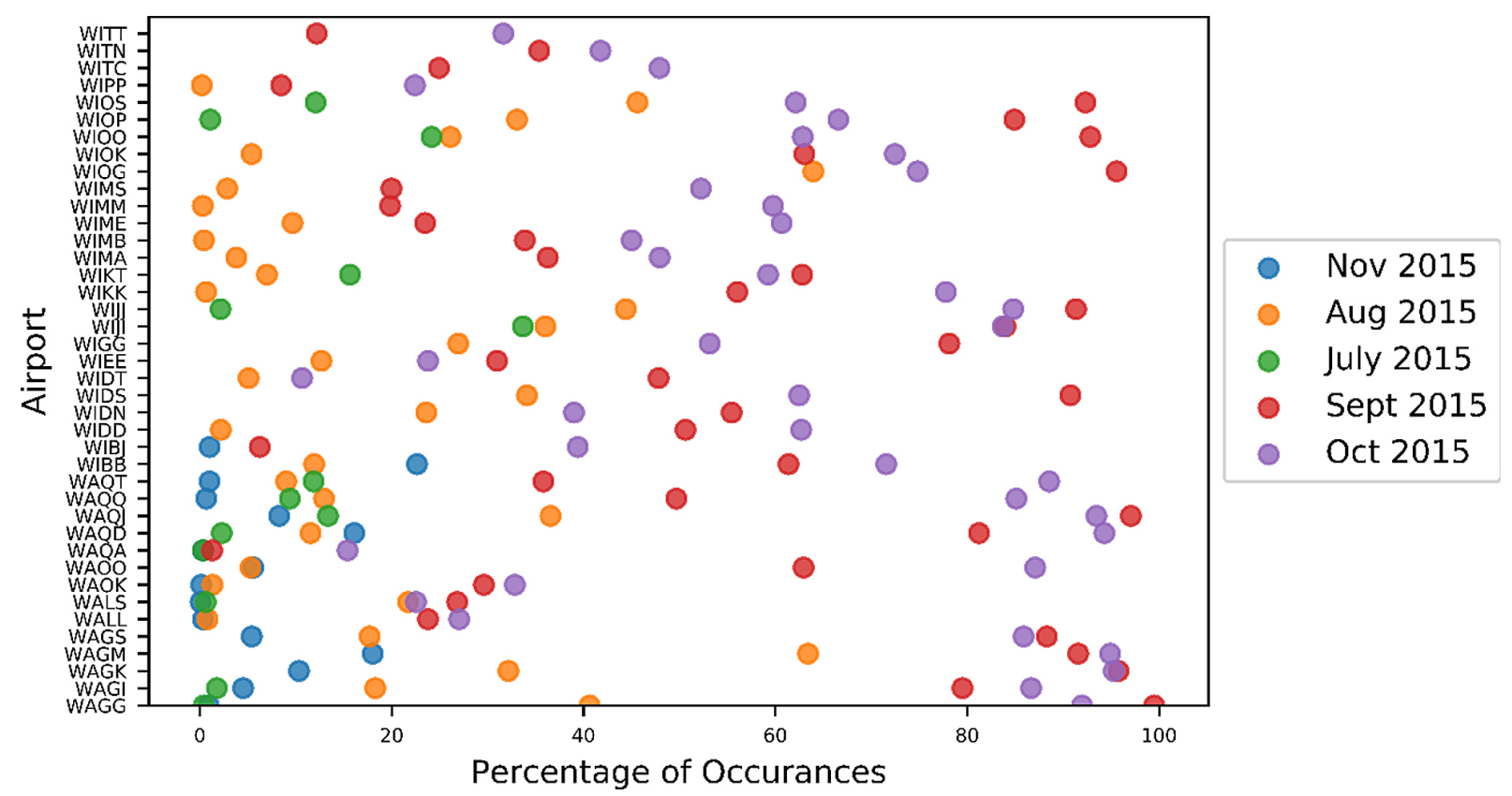

Fig. 2. Airport smoke frequency in month of July, August, September, October, and November 2015; no smoke occurred in December 2015. 
contaminated by smoke, and the horizontal axis depicts the percentage of smoke occurrence.

The Smoke occurrence at Sumatra and Borneo Island airports had monthly variations. The highest peak (climax) of smoke occurrence was detected in September and October 2015, about 40 airports were contaminated by smoke. Significant increases in occurrence realized between July, and August 2015, up to 2.5 times, from only 14 airports to 35 airports. In the period of November to December 2015, the number of contaminated airports were fallen drastically due to the research area had started entering the rainy season. Smokeaffected airports with frequencies above 75\% of the monthly data period were 15 Airports in September 2015 and 13 airports in October 2015.

\section{Daily Characteristics of Smoke Hazards at Mid-End 2015}

Figure 3 illustrated that smoke occurrence had diurnal variation. Visibility data from 43 airports (no data archive from 4 airports) were classified into 4 classes and analysed each hour. The left
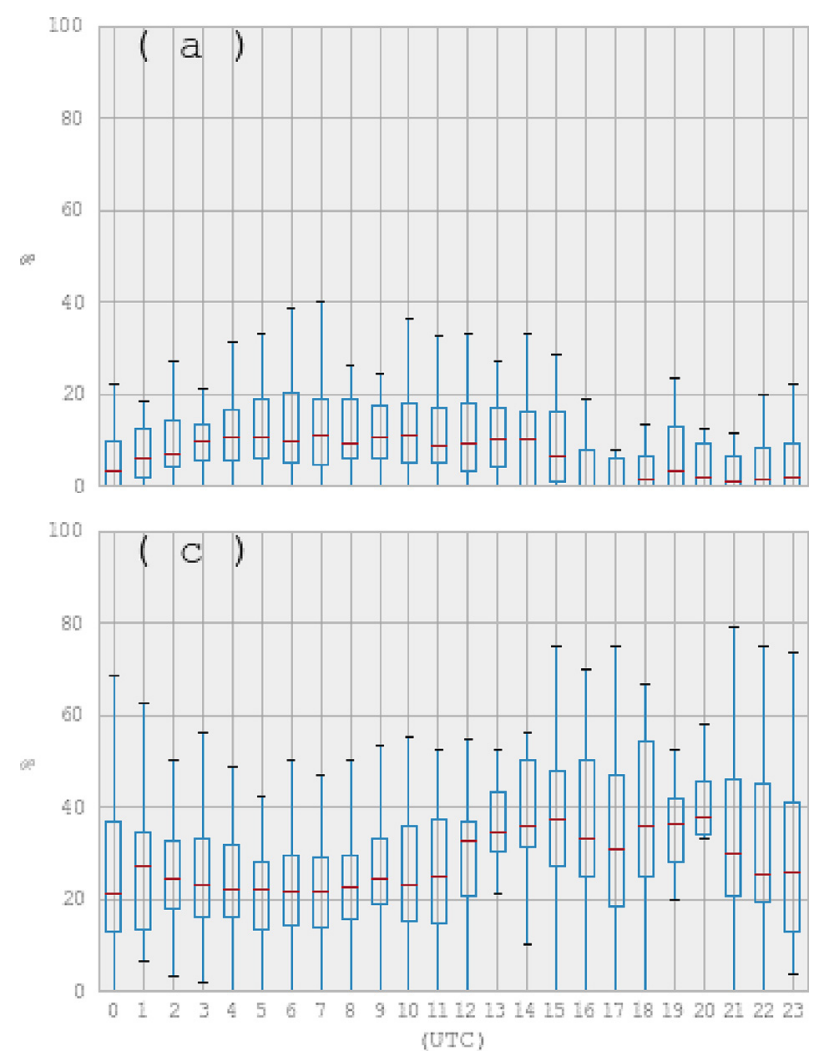

vertical axis depicts the percentages of smoke occurrence, then the horizontal axis is the daily time in Universal Time Coordinate (UTC). Each figure $(\mathrm{a}-\mathrm{d})$ are representative of each class (H1H4, that follows Table 1)

Variation of smoke-visibility daily frequency for all seasons data told the diurnal smoke-visibility characteristic. The percentages of poor visibility tended to increase successively from class $\mathrm{H} 1$ to class $\mathrm{H} 4$. The average $\mathrm{H} 1$ and $\mathrm{H} 2$ frequency of occurrences were between $0-20 \%$, while the $\mathrm{H} 3-\mathrm{H} 4$ class varies from $20 \%$ to $60 \%$. The increasing number of frequencies from $\mathrm{H} 1$ to $\mathrm{H} 4$ indicated that 2015 forest fires significantly impaired horizontal visibility. And it increased the potential hazard for aviation safety.

Visibility value due to smoke had different diurnal characteristics. Visibility during the day tended to improve, the frequency value of $\mathrm{H} 1$ and $\mathrm{H} 2$ class events tended to increase during the period of 01 to 14 UTC (around 08:00 to 21:00 WIB / local time). Visibility values tended to deteriorate (class visibility of $\mathrm{H} 3$ and $\mathrm{H} 4$ ) during the period of 14 to $01 \mathrm{UTC}$ (21.00 to $08.00 \mathrm{WIB} /$ local
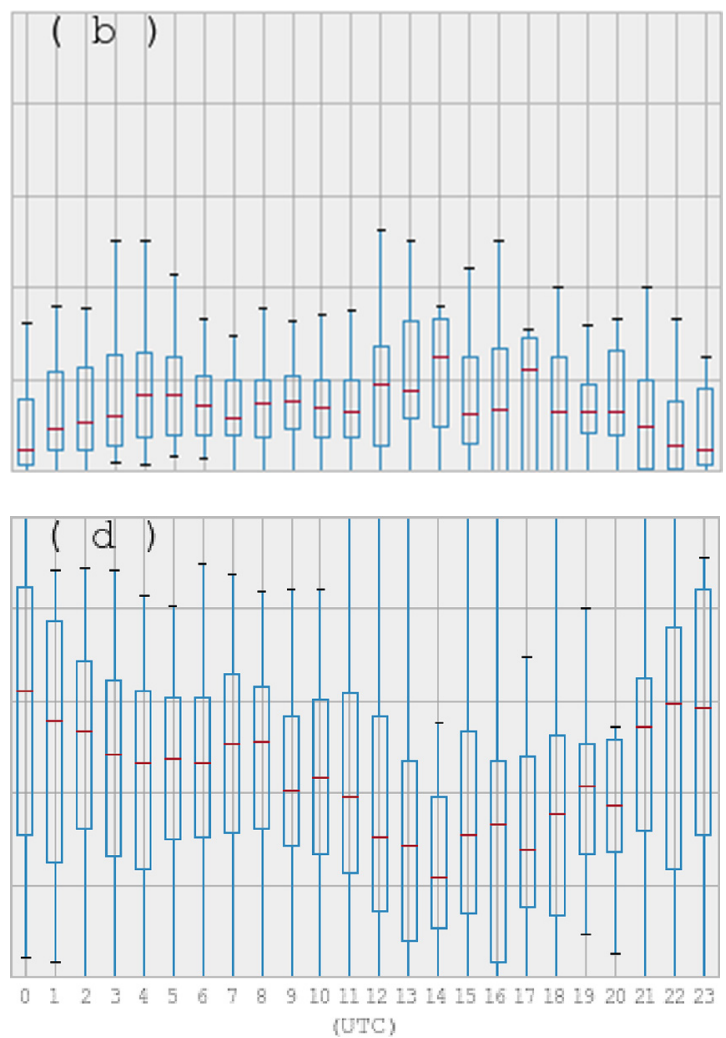

Fig. 3. Box plot diagram of visibility frequencies in a day from 42 airports with periods from July to December 2015. The impact of smoke is quantified based on visibility values (Table 1) dividing into 4 classes: H1 (VFR) (a), H2 (SVFR) (b), H3 (IFR) (c), H4 (LIFR) (d). H1: smoke with visibility > 4.8 km; H2: smoke with visibility 3.2-4.8 km; H3: smoke with visibility $1.6-3.2 \mathrm{~km}$; while $\mathrm{H} 4$ : smoke with visibility $<1.6 \mathrm{~km}$. 
time). The maximum accumulation of aerosols/ smoke particles occurred at night because there was a tendency for greater smoke emissions to occur at night (Saide et al. 2015) and due to stable air (small vertical air motion) resulting in the low atmospheric boundary layer (ABL) near the surface. While during the day there was a convection activity due to solar radiation that caused the atmosphere to be expanded and moved upwards (ABL expanded vertically) (Tosca et al. 2011). The smoke aerosol particle was expanding vertically and makes visibility value near the surface becomes even better.

The $\mathrm{H} 1$ visibility class, the minimum weather condition for VFR class, (Fig. 3 a) had an hourly mean frequency under $20 \%$ of the study period. This showed that flight with visual rules in the study period had a higher potential hazards for aviation safety because the remaining class (class H2 (Fig. 3 b), H3 (Fig. 3 c), H4 (Fig. 3 d) were more dominant. The dominance of plane crashed was the flight with VFR rules tend to continuing to operate the flight while conditions were below the minimum VFR weather, entering IMC criteria, Instrument Meteorological Conditions (Goh, Wiegmann 2002, Wiegmann et al. 2002). Violation by continuing VFR into IMC conditions specifically caused by a pilot had high confidence even not trained to deal with IMC (not having IFR flight certificate) (Jackman 2014).

\section{Spatial Characteristics of Smoke Visibility Severity Index (VSI) in Mid-End 2015}

Smoke impact on visibility was quantified based on the visibility class and the probability of the occurrence in the period of the month. This visibility severity index (VSI) was calculated based on above equation. Quantification was divided into 4 classes: very high (red circle), high (orange circle), medium (yellow circle) and low (green circle). In addition, airports that were not affected by smoke were identified as dark circles and no observational archive database with the black star. The analysis results for each month of the mid-end 2015 were described in Figure 4 a-f.

Figure 4a showed that July 2015 period was the initial phase of contamination period at airports in the research area. In total 4,361 hotspots (with the confidence level greater than 50 percent) were appearing in July 2015. Several airports (about $25 \%$ of the total airports) were experiencing moderate VSI. They are located in central Sumatra and west Borneo.

The August 2015 period (Fig. 4 b) demonstrated an increasing number of hotspots $(11,548$ hotspots in total). Nevertheless, several airports such us: WIGG-Bengkulu, WITC-Meulaboh; WILL-Lampung, WIDN-TanjungPinang, and WAOK-Kota Baru were not affected by smoke. Airports located in Riau Islands Region (WIDTTanjungBalaiKarimun, WIDD-Batam, WIDSDaboSingkep) were exposed to smoke at low VSI levels. The expansion of the visibility impact of smoke had a tendency towards to the north and to the northwest.

Figure 4c and d (September and October 2015) showed that most airports in the study area were exposed by smoke at low to very high VSI levels, except WILL-Lampung, WIII-Cengkareng Jakarta, WIHH-Halim PerdanaKusuma, and WIRR-Curug airports. They were placed on the southern site of hotspot locations. The very high VSI levels occur in the three airports, such as: WIBB-Pekanbaru, WIJJJambi, WAGG-Palangkaraya, and WIOS-Sintang.

As Fig. 4 (b, c, d) spatially indicated, VSI characteristics could be divided into three classes. The first group was airports with very high and high VSI. It was located near and/or northern site of a number of hotspots. The second group was airports with moderate to low VSI. It was generally in the northern site of a number of hotspots but had a relatively far distance. The third group (especially the area of Sumatra Island) was an airport with low VSI level to no-smoke. It was located in the west or south of a number of hotspots. Decreasing VSI level through research area revealed in the November and December 2015 period (Fig. 4 e-f). A number of hotspots remain but only caused moderate VSI to no-smoke.

The WIJJ, WIBB, WAGG, WIOS airports had very high VSI at climax smoke periods September and/or October 2015. The frequency of each visibility class and airport capacity (the rules of flight operations) seen in Table 3. Three airports have flight operation capability either VFR or IFR, while Susilo-Sintang (WIOS) Airport was only able to apply visual flight operations. Flight operations may apply if airports, planes, and pilots have technical and non-technical specifications in accordance with flight rules (Wiegmann et al. 2002). 


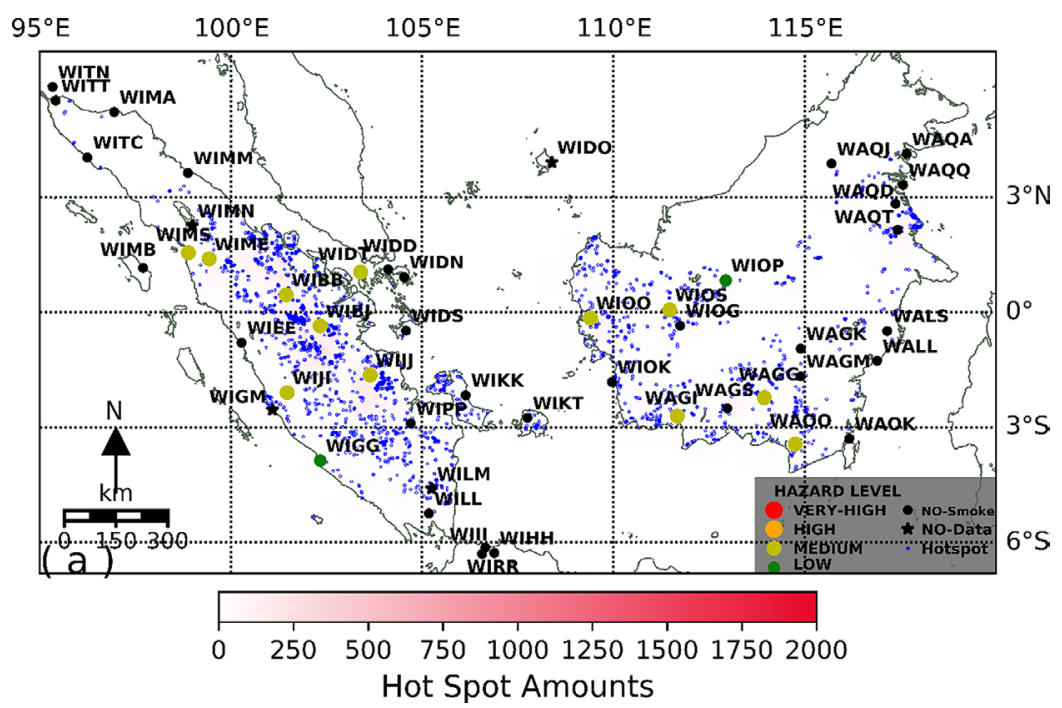

Fig. 4 a. Visibility Severity Index (VSI) July 2015. Blue dot: hotspot; hotspot density showed in a red colour heat map.

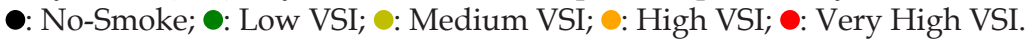

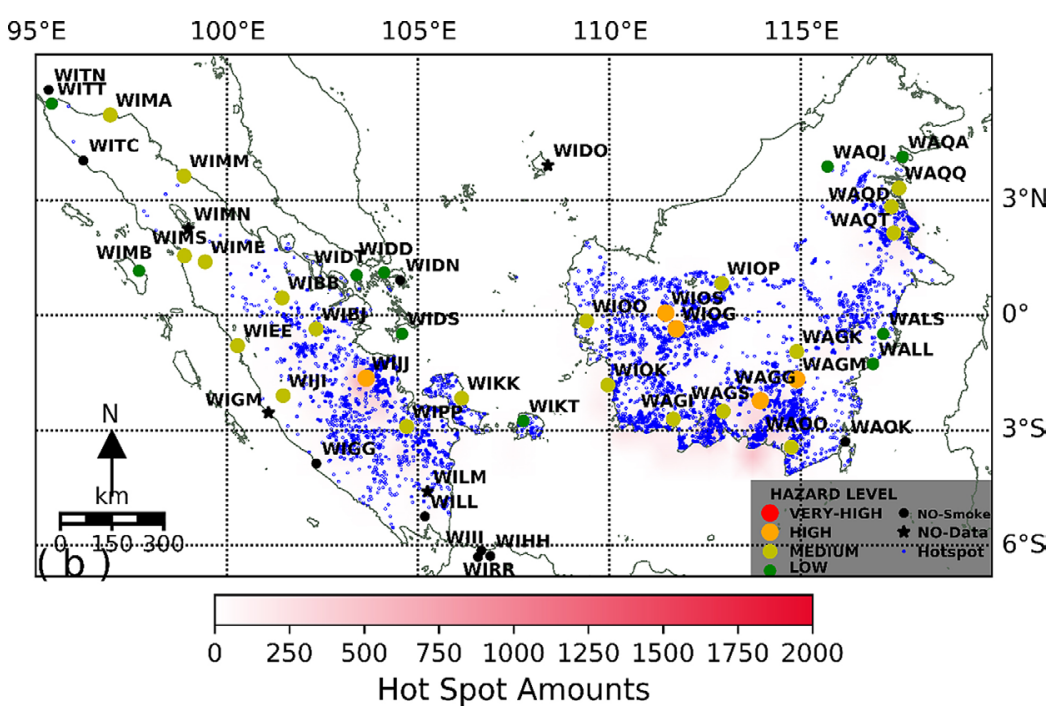

Fig. 4 b. The same as Fig. 4 a, for month August 2015.

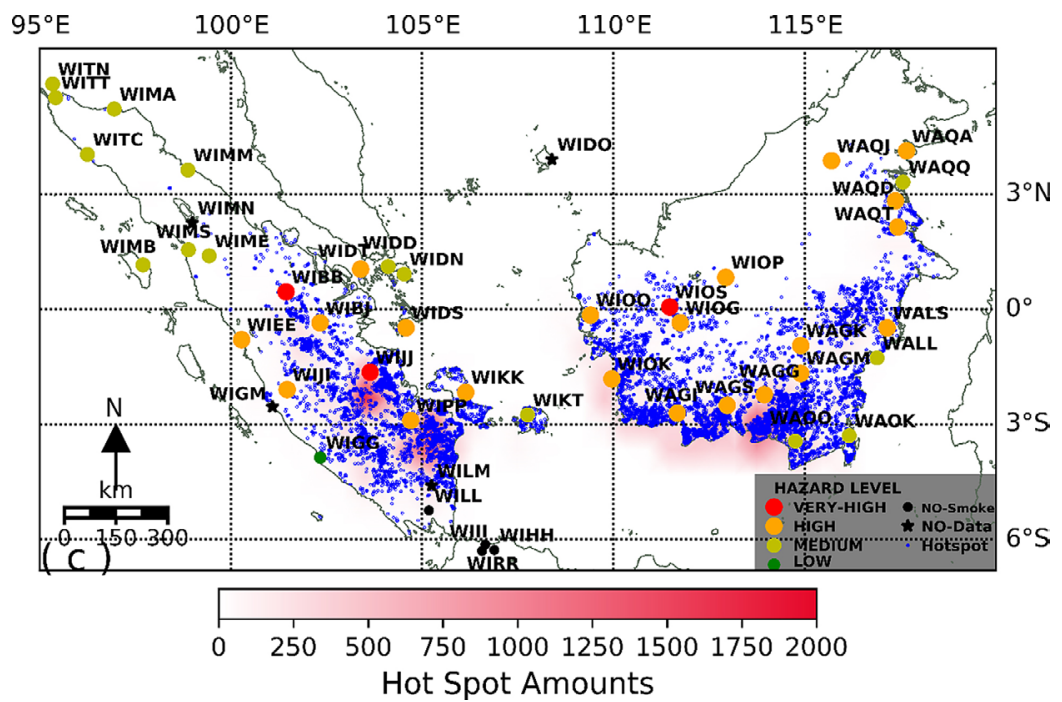

Fig. 4 c. The same as Fig. 4 a, for month September 2015. 


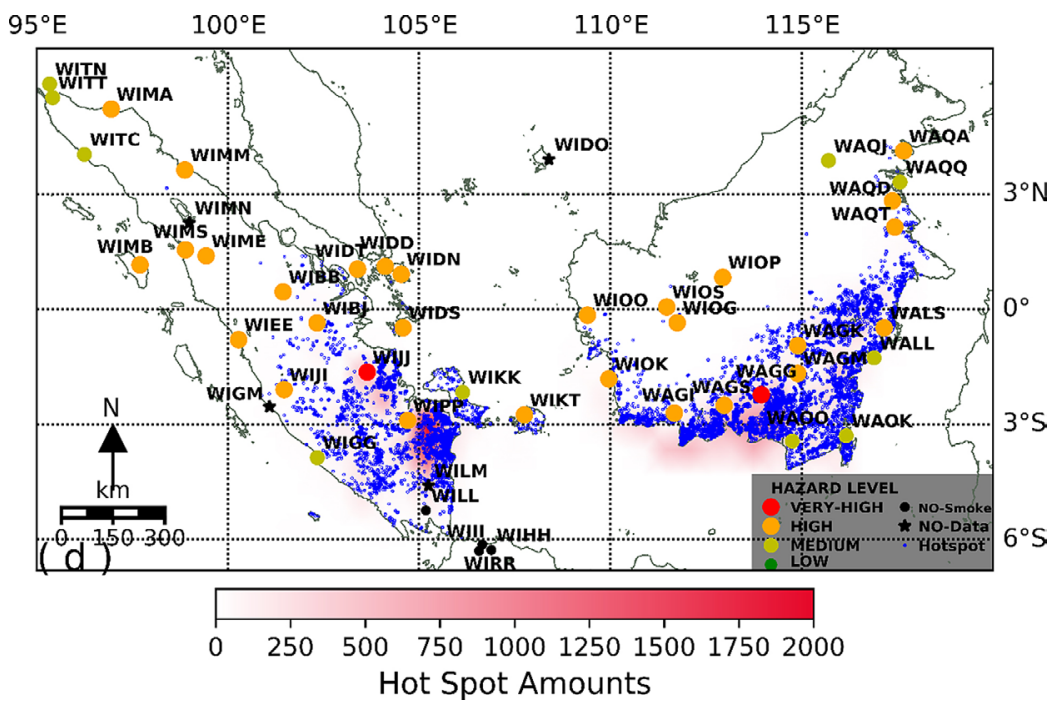

Fig. 4 d. The same as Fig. 4 a, for Month October 2015.

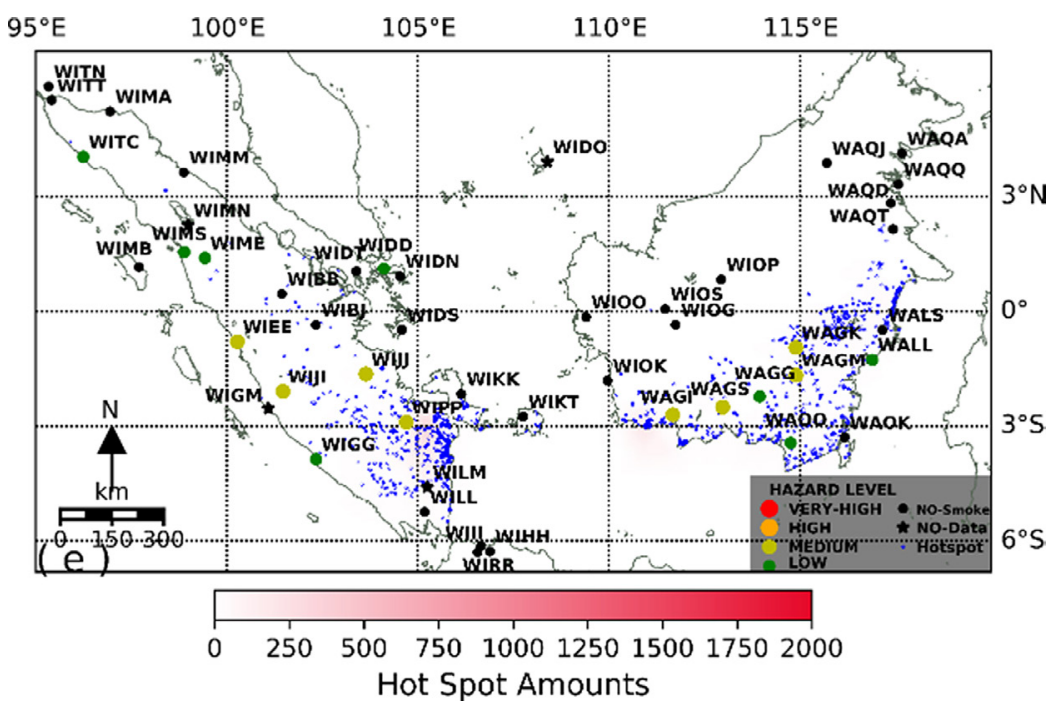

Fig. 4 e. The same as Fig. 4 a, for Month November 2015.

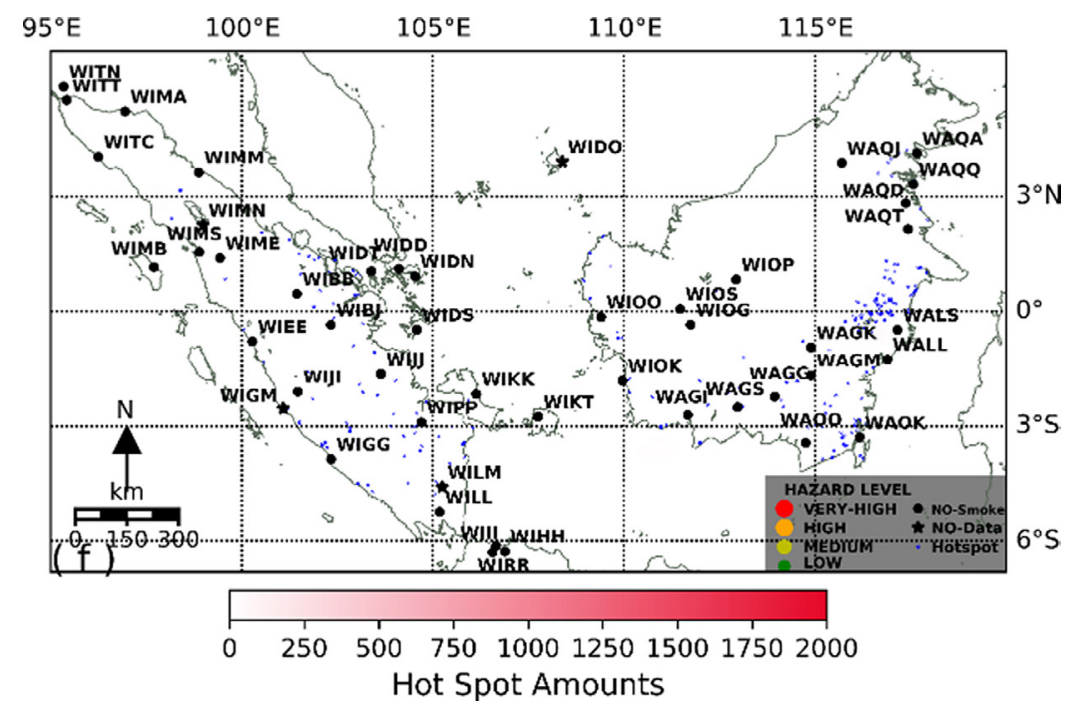

Fig. 4 f. The same as Fig. 4 a, for Month December 2015. 
Table 3. Visibility Class Frequency at very high VSI (Sources: data analysis and Indonesian aerodrome/airport chart legend (INDOAVIS 2013)).

\begin{tabular}{|c|c|c|c|c|c|c|c|}
\hline \multirow[b]{2}{*}{$\begin{array}{l}\text { Airport Code } \\
\text { (ICAO } 4 \text { Letter) }\end{array}$} & \multirow[b]{2}{*}{ Airport Name } & \multirow[b]{2}{*}{$\begin{array}{l}\text { Month } \\
(2015)\end{array}$} & \multicolumn{4}{|c|}{ Frequency (Class) } & \multirow[b]{2}{*}{ Flight Operation } \\
\hline & & & $\begin{array}{l}\text { H1 } \\
\text { (VFR) }\end{array}$ & $\begin{array}{c}\mathrm{H} 2 \\
\text { (SVFR) }\end{array}$ & $\begin{array}{l}\mathrm{H} 3 \\
\text { (IFR) }\end{array}$ & $\begin{array}{c}\mathrm{H} 4 \\
\text { (LIFR) }\end{array}$ & \\
\hline WIJJ & Sultan Thaha Jambi & October & 0.28 & 3.55 & 12.50 & 77.13 & IFR \& VFR \\
\hline WIBB & Sultan Syarif Kasim IIPekanbaru & September & 0.99 & 0.99 & 10.73 & 71.26 & IFR \& VFR \\
\hline WAGG & TjilikRiwutPalangkaraya & October & 0.29 & 1.08 & 10.71 & 79.86 & IFR \& VFR \\
\hline WIOS & SusiloSintang & September & 0.31 & 1.23 & 20.00 & 70.77 & VFR \\
\hline
\end{tabular}

In accordance with Civil Aviation Safety Regulation (CASR) Directorate General Civil Aviation (DGCA) Republic of Indonesia Number 91 Amd 4 points 91,175 (f) (DGCA 2015), the three airports (WIJJ-Jambi, WIBB-Pekanbaru, WAGG-Palangkaraya) should not serve aircraft (double engine/less) to take-off. This condition happened more than $70 \%$ of the period of the month. Visibility weather minima: less than 1.6 $\mathrm{km}$ (class H4) limitation make aircraft with double engine/less was not allowed to take off. More significant effect happened at Sintang airport, which only had the ability to carrying out VFR operations. Up to $92 \%$ of the September period could not carry out its flight operations.

\section{Conclusions}

Aerosols from forest and land fires affected the airports' visibility. Diurnal variation of improved visibility revealed at the period before noon until late at night (03-12 UTC, 10-19 local time). Decreased visibility dominant in the night until late afternoon. This diurnal variation arises from the variation in the production of different amounts of smoke between day and night (Saide et al. 2015); inversion level existence (Heil, Goldammer 2001); enhanced downdraft and shallower boundary layer (Ge et al. 2014) and large solar radiation differences during the day and night (variations of the atmospheric boundary layer) affecting aerosol concentrations to altitudes in the atmosphere (Tosca et al. 2011).

High to very high VSI level were revealed at airports near and/or northern-site of a number of hotspots. The hotspots at Sumatra and Borneo Island were dominant located over $1^{\circ} \mathrm{N}-6^{\circ} \mathrm{S}$. The VSI level spread until northern Sumatra, although the number of hotspots was low. The high VSI level spread to WIMA (MalikusalehLhoeksumawe Airport) and to the western archipelago of Sumatra WIMB (Binaka-G.Sitoli Airport). Our finding suggests that VSI spreads impact to the airports have a close relationship with smoke transport. Revealed in Figure 5, the low-level south-easterly wind has flowed persistently during the July-November 2015, it strong propagated smoke from the south and central Sumatra to the Northern side of Sumatra. This trade wind was suggested as the dominant factor for VSI spreads, in addition (Wang et al. 2013) showed that other wind factors related to the smoke transport are land/sea breeze, typhoon and storm over Subtropical Western Pacific, and topographic effect. While on the Island of Borneo, VSI spread tend to homogenous around the airports in the island. It reaches medium to very high VSI level. It suggests that smoke propagation was still influenced by trade wind that is south-eastern wind, south of Equator and north-eastern wind, north of Equator.

Our finding revealed that the three airports, which had to have very high VSI, whose implemented instrument flight rule could, operate flight only $24 \%$ time operation with allowed visibility minimum condition. The rest, $76 \%$ time operations, were facing visibility under $1600 \mathrm{~m}$ (IFR visibility below minima) at smoke climax period month. According to the CASR part 91 point 91.175. (d) No pilot operating an aircraft may land with such visibility (DGCA 2015). Flight under IFR means flight based on air traffic controller (ATC) monitoring. Before manoeuvring, aircraft must obtain a clearance from ATC to remain safely separated (Wangermann 2003). To avoid a collision, aircraft should wait until weather conditions have improved or flight into alternate airports. 
While the airport with only visual flight operations (VFR), Sintang-Airport, experienced about $92 \%$ of IFR visibility below minima condition at smoke climax period month. Pilots who are operating under Visual Flight Rules (VFR) encounter with instrument meteorological conditions (IMC) have a substantial portion of the fatal accidents among general aviation aircraft (Hunter et al. 2011). Under adverse conditions/visibilitybelow minima, the pilot could not be continuing flight operations until weather conditions improve in accordance with the minimum permissible limit (DGCA 2015) or land at the nearest suitable aerodrome (ICAO 2012).
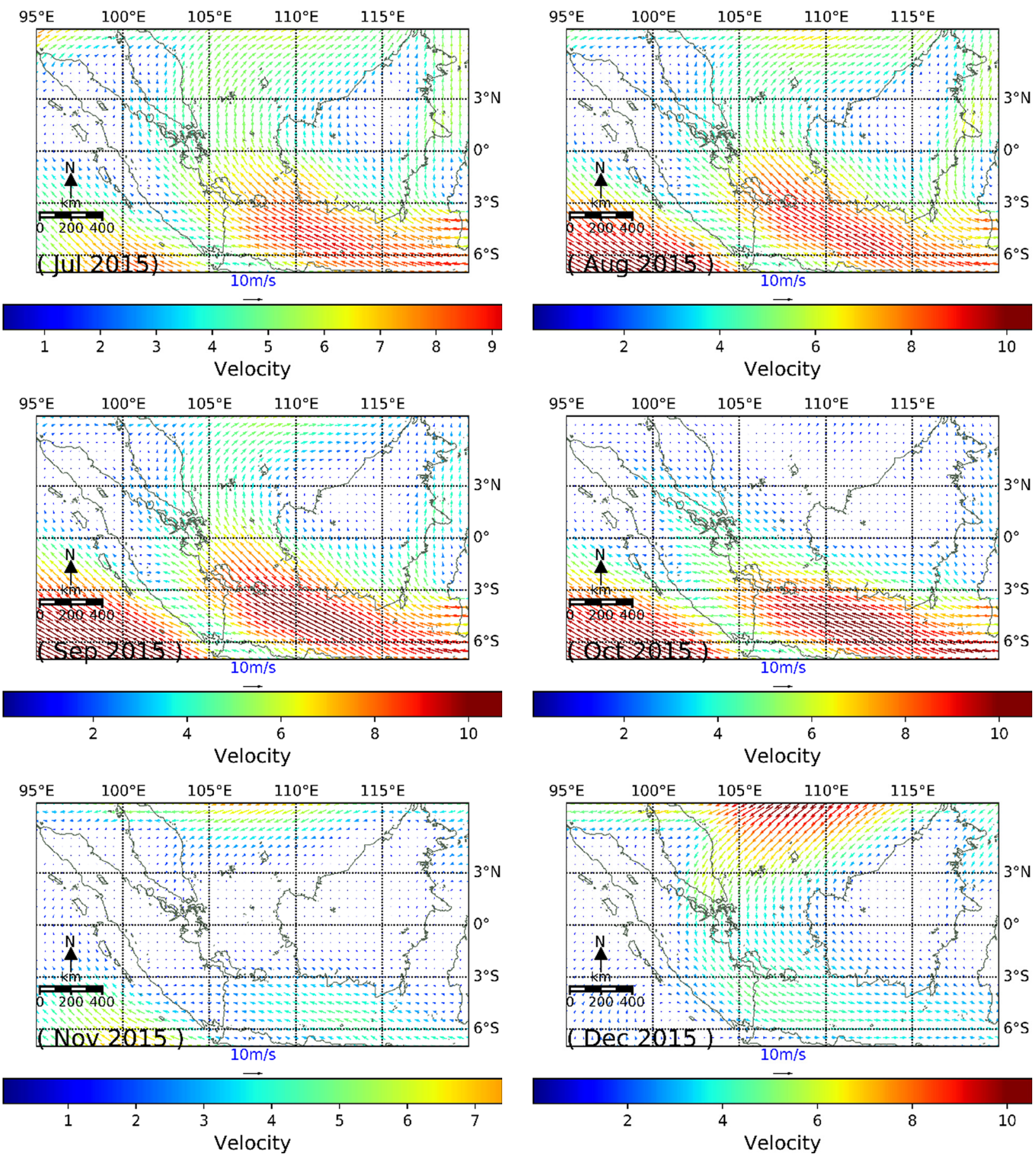

Fig. 5. Monthly mean wind level $\pm 762 \mathrm{~m}$ (925 mbar) $0.5 \times 0.5$ degree ECMWF model for period from July to December 2015. 


\section{Acknowledgements}

This work is supported by centre for education and training of Meteorological, Climatological and Geophysical Agency's (BMKG, Indonesia) funding. Many thanks to Head of centre for education and training BMKG Mr. Maman Sudarisman DEA for all your kind supports.

\section{Authors Contribution}

HI: conceived of the presented idea, developed the theory and performed the computation and analysis. $\mathrm{HH}$ : encourage first author to investigate and digging the aviation information related to paper topic, supervised the findings of this work and language correction. MAM: conceived of the presented idea, developed the theory, supervised the findings of this work and as corresponding author. All authors discussed the results and contributed to the final manuscript.

\section{References}

Afrianto Y., Marfai M.A., Hadi M.P., 2015. Pemodelan Bahaya Banjir dan Analisis Risiko Banjir Studi Kasus: Kerusakan Tanggul Kanal Barat Jakarta Tahun 2013. Majalah Geografi Indonesia 29(1): 95-110.

Aiken S.R., 2004. Runaway fires, smoke-haze pollution, and unnatural disasters in Indonesia. Geographical Review 94: 55-79.

Baccini A., 2001. Frequentist Probability and Choice under Uncertainty Frequentist Probability and Choice under Uncertainty. History of Political Economy, (February). DOI: 10.1215/00182702-33-4-743.

Balarabe M., Abdullah K., Nawawi M., 2015. Long-Term Trend and Seasonal Variability of Horizontal Visibility in Nigerian Troposphere. Atmosphere 6(10): 1462-1486. DOI: 10.3390/atmos6101462.

CWB [Central Weather Bureau], n.d. Haze. Online: www. cwb.gov.tw/V7e/knowledge/encyclopedia/me014.htm (accessed 15 October 2017).

DGCA [Director General of Civil Aviation], 2015. General Operation and Flight Rules (Civil Avia). Indonesia: Diretorate General Civil Avition. Republic of Indonesia Ministry of Transportation.

ECMWF [European Centre for Medium-Range Weather Forecasts], 2018. ERA5 Catalogue. Online: apps.ecmwf. int/data-catalogues/era5/?class=ea (accessed 1 September 2018).

FAA [Federal Aviation Administration], 2009. General Aviation Pilot's Guide to Preflight Weather Planning, Weather Self-Briefings, and Weather Decision Making.

Ge C., Wang J., Reid J.S., 2014. Mesoscale modeling of smoke transport over the Southeast Asian maritime continent: Coupling of smoke direct radiative effect below and above the low-level clouds. Atmospheric Chemistry and Physics 14(1): 159-174. DOI: 10.5194/acp-14-159-2014.

Giglio L., 2010. MODIS Collection 5 Active Product User's Guide. Online: modis-fire.umd.edu/files/MODIS_Fire_ Users_Guide_2.5.pdf (accessed 12 March 2019).
Glahn B., Schanpp D., Im J., 2015. The Lamp and HRRR Ceiling Height and Visibility MELD.

Goh J., Wiegmann D., 2002. Human factors analysis of accidents involving visual flight rules flight into adverse weather. Aviation Space and Environmental Medicine 73(8): 817-822.

Gunawan A., 2015. Airlines calculate losses due to haze (2015 10 01). Online: www.thejakartapost.com/news/ 2015/10/01/airlines-calculate-losses-due-haze.html (accessed 1 January 2018).

Hantson S., Padilla M., Corti D., Chuvieco E., 2013. Strengths and weaknesses of MODIS hotspots to characterize global fire occurrence. Remote Sensing of Environment 131: 152-159. DOI: 10.1016/j.rse.2012.12.004.

Heil A., Goldammer G., 2001. Smoke-haze pollution : a review of the 1997 episode in Southeast Asia. Regional Environmental Change 2: 24-37. DOI: 10.1007/s101130100021.

Heil A., Langmann B., Aldrian E., 2007. Indonesian peat and vegetation fire emissions: Study on factors influencing large-scale smoke haze pollution using a regional atmospheric chemistry model. Mitigation and Adaptation Strategies for Global Change 12: 113-133. DOI: 10.1007/s11027006-9045-6.

Herzegh P., Wiener G., Bateman R., Cowie J., Black J., 2015. Flight safety data fusion enables better recognition of ceiling and visibility hazards in aviation. American Meteorological Society, (April). DOI: 10.1175/BAMS-D-13-00111.1.

Hunter D.R., Martinussen M., Wiggins M., O'Hare D., 2011. Situational and personal characteristics associated with adverse weather encounters by pilots. Accident Analysis and Prevention 43(1): 176-186.

ICAO [International Civil Aviation Organization], 2011. Doc. 8896 Manual of Aeronautical Meteorological Practice (Ninth Edit). Montreal, Quebec, Canada.

ICAO [International Civil Aviation Organization], 2012. Rules of the Air, Annex 2 to the Convention on International Civil Aviation. DOI: 10.1007/978-3-642-25835-0.

ICAO [International Civil Aviation Organization], 2013. Doc 9859 Safety Management Manual (SMM) (Third Edit). Montreal, Quebec, Canada: International Civil Aviation Organization.

INDOAVIS, 2013. Aerodrome / Airport Diagram Chart Legend. PT. INDOAVIS NUSANTARA.

Ismanto H., Hartono H., Marfai M.A., 2018. Smoke detections and visibility estimation using Himawari ${ }_{-} 8$ satellite data over Sumatera and Borneo Island Indonesia. Spatial Information Research 27(2): 205-216. DOI: 10.1007/ s41324-018-0225-8.

Jackman B., 2014. Policy violations predicting fatal general aviation accident from visual flight rules to instrument meteorological conditions.

Janic M., 2000. An assessment of risk and safety in civil aviation. Journal of Air Transport Management 6: 43-50.

Jenamani R.K., Kumar A., 2013. Bad weather and aircraft accidents - global vis-a-vis Indian scenario. Current Science 104(3): 316-325.

Lari S., Frattini P., Crosta G.B., 2014. A probabilistic approach for landslide hazard analysis. Engineering Geology 182: 3-14. DOI: 10.1016/j.enggeo.2014.07.015.

McKirdy E., 2015. Southeast Asia's haze crisis: A “crime against humanity". Online: www.edition.cnn. com/2015/10/29/asia/southeast-asia-haze-crisis/index.htm (accessed 23 February 2016).

Michoud C., Derron M., Horton P., Jaboyedoff M., Baillifard F.-J., Loye A., Nicolet P., Pedrazzini A., Queyrel A., 
2012. Rockfall hazard and risk assessments along roads at a regional scale : example in Swiss Alps. Natural Hazards and Earth System Sciences 12: 615-629. DOI: 10.5194/ nhess-12-615-2012.

Oster C.V, Strong J.S., Zorn C.K., 2013. Analyzing aviation safety : Problems, challenges, opportunities. Research in Transportation Economics 43(1): 148-164. DOI: 10.1016/j. retrec.2012.12.001.

Rashid I., Parvez I.A., Ahmad S., 2018. Seismic hazard and probability assessment of Kashmir. Natural Hazards 93(3): 1451-1477. DOI: 10.1007/s11069-018-3362-4.

Rudack D.E., Ghirardelli J.E., 2010. A Comparative Verification of Localized Aviation Model Output Statistics Program ( LAMP ) and Numerical Weather Prediction ( NWP ) Model Forecasts of Ceiling Height and Visibility. Weather and Forecasting 25: 1161-1178. DOI: 10.1175/2010WAF2222383.1.

Saide P.E., Peterson D.A., da Silva A., Anderson B., Ziemba L.D., Diskin G., Sachse G., Hair J., Butler C., Fenn M., Jimenez J.L., Campuzano-Jost P., Perring A.E., Schwarz J.P., Markovic M.Z., Russell P., Redemann J., Shinozuka Y., Streets D.G., Yan F., Dibb J., Yokelson R., Toon O.B., Hyer E., Carmichael G.R., 2015. Revealing important nocturnal and day-to-day variations in fire smoke emissions through a multiplatform inversion. Geophysical Research Letters 42: 3609-3618. DOI: 10.1002/2015GL063737.

State-Argentina. 2016. Risk Index - Algorithm to Assess Probability (No. A39-WP/188). Online: www.icao.int/Meetings/a39/Documents/WP/wp_188_en.pdf (accessed 12 march 2019).

Tosca M.G., Randerson J.T., Zender C.S., Nelson D.L., Diner D.J., Logan J.A., 2011. Dynamics of fire plumes and smoke clouds associated with peat and deforestation fires in Indonesia. Journal of Geophysical Research 116: 1-14. DOI: 10.1029/2010JD015148.

Wang J., Ge C., Yang Z., Hyer E.J., Reid J.S., Chew B.N., Zhang M., 2013. Mesoscale modeling of smoke transport over the Southeast Asian Maritime Continent: Interplay of sea breeze, trade wind, typhoon, and topography. Atmospheric Research 122: 486-503. DOI: 10.1016/j.atmosres.2012.05.009.

Wang Y., Field R.D., Roswintiarti O., 2004. Trends in atmospheric haze induced by peat fires in Sumatra Island, Indonesia and El Nino phenomenon from 1973 to 2003. Geophysical Research Letters 31(4): 1-4. DOI: 10.1029/2003GL018853.

Wangermann J.P., 2003. Principled negotiation and distributed optimization for advance air traffic management. Princeton University.

Widodo A.M., Dulbahri D., Hartono H., 2017. Penggunaan Data Penginderaan Jauh dan Sistem Informasi Geografis untuk Pembuatan Prototipe Perangkat Lunak Simulasi Penyebaran Kebakaran Hutan. Majalah Geografi Indonesia 31(1): 12-21.

Wiegmann D.A., Goh J., O’Hare D., 2002. The role of situation assessment and flight experience in pilots' decisions to continue visual flight rules flight into adverse weather. Human Factors 44(2): 189-197.

Xian P., Reid J.S., Atwood S.A., Johnson R.S., Hyer E.J., Westphal D.L., Sessions W., 2013. Smoke aerosol transport patterns over the Maritime Continent. Atmospheric Research 122:, 469-485. DOI: 10.1016/j.atmosres.2012.05.006. 